\title{
Análise da participação popular na política de atenção à saúde da pessoa com deficiência em Aracaju, Sergipe, Brasil
}

Marcus Valerius da Silva Peixoto(a)

Géssica Santana Santos ${ }^{(b)}$

Gabriela Rodrigues Dourado Nobre ${ }^{(c)}$

Ana Paula de Souza Novais(d)

Paloma Martins Reis(e)

Peixoto MVS, Santos GS, Nobre GRD, Novais APS, Reis PM. Analysis of popular participation in healthcare policy for people with disabilities in Aracaju, Sergipe, Brazil. Interface (Botucatu). 2018; 22(67):1099-110.

The aim of the present article is to analyze the role of civil society in healthcare policymaking for people with disabilities in the municipality of Aracaju, Sergipe, Brazil. This was a qualitative study with semistructured interviews with representatives of the Council for the Defense of the Rights of People with Disabilities. The data were analyzed according to thematic content analysis. The results show that the representatives held diffuse understandings of the concept of disability, shifting among existing paradigms. Special mention goes to the difficulty presented by the representatives to propose issues for the local political agenda and participate in the creation and implementation of public health policy, creating a gap between social control organizations and public management.

Keywords: Health policymaking. Social control. Public policies.
Este artigo objetiva analisar o papel da sociedade civil na política de saúde da pessoa com deficiência no município de Aracaju-SE. Foi realizado um estudo qualitativo com entrevistas semiestruturadas com representantes do Conselho de Defesa dos Direitos da Pessoas com Deficiência. Os dados foram analisados de acordo com a análise temática de conteúdo. Os resultados demonstram que o entendimento da concepção da deficiência, por parte dos representantes da sociedade civil, é difuso, transitando entre os paradigmas existentes. Foi notável a dificuldade dos representantes em propor temas para a agenda política no âmbito local e participar na formulação e implementação da política pública de saúde, criando um distanciamento entre os órgãos de controle social e gestão.

Palavras-chave: Formulação de políticas de saúde. Controle social. Políticas públicas.

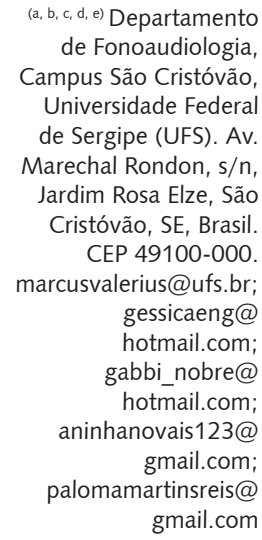

$(a, b, c, d, e)$ Departamento de Fonoaudiologia, Campus São Cristóvão, Universidade Federal de Sergipe (UFS). Av. Marechal Rondon, s/n, Jardim Rosa Elze, São Cristóvão, SE, Brasil. CEP 49100-000. marcusvalerius@ufs.br; gessicaeng@ hotmail.com; gabbi_nobre@ hotmail.com; aninhanovais123@ gmail.com;

palomamartinsreis@ gmail.com 


\section{Introdução}

Ao longo dos anos, a deficiência foi vista como uma perturbação do funcionamento biológico, ligada a um atributo individual que tornava o sujeito incapaz de trabalhar e desenvolver tarefas cotidianas. No entanto, não existe uma sentença predestinada, mas, sim, um prejulgamento da sociedade que não está preparada para compreender as diferenças'1.

Segundo a Convenção Mundial sobre os Direitos das Pessoas com Deficiência: "Pessoas com deficiência são aquelas que têm impedimentos de natureza física, intelectual ou sensorial, os quais, em interação com diversas barreiras, podem obstruir sua participação plena e efetiva na sociedade com as demais pessoas"2. A deficiência é considerada, portanto, uma condição social caracterizada pela limitação ou impedimento da participação da pessoa com deficiência nos diferentes âmbitos de tomada de decisões na sociedade.

As pessoas com deficiência possuem necessidades de saúde que precisam ser respondidas pelos serviços, programas e políticas de Estado, uma vez que estas necessidades perpassam pela acessibilidade, apoio psicossocial, aspectos gerais de saúde, autonomia e independência; equipamentos e tecnologia assistiva, informação, prevenção e diagnóstico precoce; reconhecimento de garantias e direitos; reencontro com atividades significativas, validação e ajuda nas estratégias de enfrentamento, e o vínculo com o profissional de saúde ${ }^{3}$.

No Brasil, de acordo com dados do Instituto Brasileiro de Geografia e Estatística - IBGE, aproximadamente $24 \%$ da população brasileira declararam possuir algum tipo de deficiência ${ }^{4}$. Apesar da magnitude do problema, o Brasil possui um histórico de políticas de saúde fragmentadas no que diz respeito a esta população $0^{5-7}$.

O Sistema Único de Saúde - SUS foi criado sob a premissa de que saúde é um direito de todos e dever do Estado, possuindo, como um dos seus princípios, o controle social, com a função de integrar a sociedade civil com a gestão pública na resolução de problemas e necessidades sociais. Desta forma, cabe à sociedade civil, mediante instâncias de controle social: exercer um efetivo controle dos governantes, moldando as ações do Estado, bem como exigir transparência no repasse dos recursos financeiros; conhecer as necessidades reais da população, instaurando um espaço fértil de diálogo mediante os conselhos de saúde ${ }^{8}$.

A sociedade civil influencia diretamente as políticas públicas de saúde, podendo interferir na formulação, implementação e avaliação, visando à definição das necessidades em saúde de cada momento histórico, defendendo os interesses da coletividade e garantindo um maior comprometimento do governo?.

Os espaços participativos podem ser tipificados em: Conselhos de Políticas Públicas, Conselhos de Fundos e Conselhos de Direitos, de modo que este último tem a finalidade de atender prioritariamente as necessidades de marginalizados do sistema político, movimentos populares e identitários. São conselhos que buscam políticas transversais por grupos específicos de situações em que pessoas têm seus direitos sistematicamente desrespeitados por meio de discriminação, seja explícita ou implícita ${ }^{10}$.

O seguimento da pessoa com deficiência encontra, nos Conselhos de Direitos, um espaço de debates e lutas na busca da garantia da proteção social do Estado. A maior representação nacional consiste no Conselho Nacional dos Direitos da Pessoa com Deficiência - CONADE, órgão superior de deliberação colegiada, criado para acompanhar e avaliar o desenvolvimento de uma política nacional para inclusão da pessoa com deficiência e das políticas setoriais de: educação, saúde, trabalho, assistência social, transporte, cultura, turismo, desporto, lazer e ações urbanas dirigidas a esse grupo social ${ }^{11}$.

Um dos papéis do CONADE é fortalecer a rede de conselhos para que as pessoas com deficiência tenham espaços locais de protagonismo e participação direta na implantação e monitoramento das políticas públicas. O CONADE, assim como os conselhos municipais e estaduais, devem ter participação paritária entre membros do Estado (organizações governamentais) e sociedade civil (movimentos sociais e organizações não governamentais) ${ }^{11}$.

A participação popular na gestão pública garante que os mais diversos movimentos sociais influenciem as políticas públicas com base nas demandas sociais, assegurando a democracia no país ${ }^{12}$. 
No entanto, ressalta-se que a efetividade do controle social só será possível a partir do momento em que os conselhos se tornarem verdadeiramente um espaço de democracia participativa, ou seja, um espaço para interceder nos interesses e conflitos entre os mais diversos seguimentos da sociedade. Não se sabe ao certo os limites e possibilidades desses espaços representativos e qual a influência e conhecimento da sociedade civil no processo decisório. Assim, abre-se um leque de questionamentos acerca daqueles que representam o povo, exercendo o controle social ${ }^{13}$.

A Organização Mundial da Saúde - OMS produziu o Relatório Mundial sobre a Deficiência em 2011, com o intuito de oferecer, aos governantes, líderes de Estado e à sociedade civil, o conhecimento de como melhorar a acessibilidade e igualdade de oportunidades, promover a participação, inclusão, autonomia e dignidade das pessoas com deficiência ${ }^{14}$.

No mesmo ano, um conjunto de medidas foi publicado no Brasil, contidas no Plano Nacional de Direitos da Pessoa com Deficiência, chamado de Plano Viver sem Limite, o qual se apresenta em quatro eixos: Acesso à Educação; Inclusão Social; Atenção à Saúde, e Acessibilidade. Cada ação presente nesses eixos é interdependente e articulada com as demais, construindo redes de serviços e políticas públicas capazes de assegurar um contexto de garantia de diretos para as pessoas com deficiência, considerando suas múltiplas necessidades nos diferentes momentos de suas vidas ${ }^{15}$.

No âmbito da saúde, formulou-se a Rede de Cuidados à Pessoa com Deficiência, que tem como objetivo ampliar a integração e articulação dos serviços de reabilitação com a rede de atenção primária, especializada e hospitalar, promovendo atenção integral à saúde e a qualificação do atendimento às pessoas com deficiência ${ }^{16}$. A nova rede propôs colaborar com a superação de visões que privilegiem o reconhecimento da pessoa com deficiência exclusivamente pela lógica bioidentitária a partir da condição biológica e isolacionismo social ${ }^{5}$.

Ressalta-se a importância da mobilização de grupos sociais para criar situações favoráveis, chamadas de "janelas de oportunidades", na definição de problemas que envolve a participação do Estado e grupos sociais de interesse na demarcação de um assunto público por meio de intensa negociação. Existe um jogo de tensão entre as partes de interesse que permeia todo o ciclo de uma política pública, desde a entrada na agenda à sua formulação, implementação e avaliação ${ }^{17}$.

Diante da criação de um marco político no campo da saúde da pessoa com deficiência, bem como do papel que os conselhos de direitos da pessoa com deficiência podem exercer na sociedade, este artigo teve como objetivo analisar a participação popular na política de saúde da pessoa com deficiência no âmbito municipal.

\section{Metodologia}

Foi realizado um estudo de cunho qualitativo no município de Aracaju-SE. As técnicas e procedimentos para a produção de dados foram: entrevistas semiestruturadas aplicadas com os representantes das pessoas com deficiência, os quais atuam em espaços de controle social, a saber, o Conselho Municipal de Defesa de Direitos da Pessoa com Deficiência. A representação dos atores está ligada aos movimentos sociais e organizações não governamentais. As entrevistas foram gravadas em áudio e transcritas para análise. Foram utilizados, também, diários de campo, com anotações, comportamentos descritos e reflexões. Foram entrevistadas sete pessoas (informantes-chave) no total.

Optou-se por entrevistar exclusivamente os representantes da sociedade civil no sentido de produzir uma maior aproximação das pessoas com deficiência, dos seus movimentos e entidades, bem como evitar possíveis assimetrias de poder dos agentes públicos do Estado por ocuparem funções no aparato burocrático-institucional que venham a neutralizar ou anular interesses da sociedade civil. Os informantes-chave da pesquisa são caracterizados conforme os dados dispostos no quadro 1, incluindo: o tipo de entidade que o sujeito representa, a função que exerce (vínculo de trabalho assalariado, trabalho voluntário, militante ou dirigente), bem como se o sujeito possui ou não algum tipo de deficiência. 
Quadro 1. Características dos participantes da pesquisa

\begin{tabular}{|c|l|l|l|}
\hline Informante & \multicolumn{1}{|c|}{ Representação } & \multicolumn{1}{|c|}{ Função } & \multicolumn{1}{|c|}{ Deficiência } \\
\hline A & $\begin{array}{l}\text { Organização não Governamental de Pessoas com Deficiência } \\
\text { Intelectual }\end{array}$ & Trabalhador(a) & Sem Deficiência \\
\hline B & $\begin{array}{l}\text { Organização não Governamental de Pessoas com Deficiência } \\
\text { Intelectual }\end{array}$ & Voluntário(a) & Sem Deficiência \\
\hline C & Movimento Social ligado às Pessoas com Deficiência Física & Militante & Deficiência Física \\
\hline D & $\begin{array}{l}\text { Organização não Governamental de Pessoas com Deficiência Física } \\
\text { e Intelectual }\end{array}$ & Voluntário(a) & Sem Deficiência \\
\hline E & Sem vínculo com Entidades & Militante & Sem Deficiência \\
\hline F & $\begin{array}{l}\text { Organização não Governamental de Pessoas com Deficiência Física } \\
\text { e Intelectual }\end{array}$ & Dirigente de Entidade & Sem Deficiência \\
\hline G & Organização não Governamental de Pessoas Surdas & Voluntário(a) & Sem Deficiência \\
\hline
\end{tabular}

Os sujeitos da pesquisa foram compreendidos como "atores sociais" com o potencial para: analisar determinada conjuntura política no âmbito nacional, estadual e local; propor temas para agenda; protagonizar o processo de formulação, implementação e avaliação das ações voltadas para a saúde da pessoa com deficiência, expressando as demandas sociais.

As entrevistas foram transcritas e analisadas à luz da Análise Temática do Conteúdo de Minayo ${ }^{18}$. A análise se desdobrou em três etapas: $1^{a}$ pré-análise, a qual foi composta por uma "leitura flutuante", contemplando um contato intenso com o material e impregnação pelo conteúdo com um movimento entre as hipóteses iniciais e hipóteses emergentes. Foi realizada, também, uma segunda tarefa, que compreende a constituição do corpus, contemplando normas de validação mediante a homogeneidade e representatividade. $\mathrm{Na} 2^{a}$ exploração do material, foram levantadas categorias, selecionadas as unidades de registro, e os dados foram categorizados de acordo com os temas.

Foram criadas cinco categorias para análise e discussão: A trajetória dos atores; Concepção da política de saúde da pessoa com deficiência; Necessidades de saúde; Janela de oportunidades, e Conformação da agenda política.

\section{Aspectos Éticos}

O projeto foi aprovado pelo Comitê de Ética e Pesquisa com o número 798.182. As participações foram voluntárias, com assinatura do Termo de Consentimento Livre e Esclarecido (TCLE).

\section{Resultados e Discussão}

\section{Trajetória dos atores}

Uma vez feita a análise dos dados, foi percebido que os atores percorreram percursos distintos até se tornarem representantes da sociedade civil no tocante aos direitos da pessoa com deficiência. Um dado relevante foi o fato de a maioria dos atores não estar na condição de pessoa com deficiência, o que, em alguma medida, contradiz o mote encampado pela Convenção Mundial sobre os Direitos da Pessoa com Deficiência: "Nada sobre nós sem nós". Foi observada a necessidade de se compreender melhor tal composição mediante a categoria da "trajetória dos atores".

Nesse sentido, vêm à tona três hipóteses de trajetórias que levaram cidadãos a se tornarem representantes das pessoas com deficiência. Foram traçadas três trajetórias a partir dos relatos obtidos: trajetória burocrático-institucional, trajetória ligada aos vínculos afetivos e, por fim, a transformação de um vínculo burocrático-institucional ou afetivo na trajetória de engajamento político. 


\section{Trajetória burocrático-institucional}

Alguns atores tornaram-se conselheiros devido a uma imposição institucional da entidade que eles vieram representar. Essa imposição induz ao pensamento de que uma parcela dos informantes-chave ocupa espaços nos conselhos em virtude do cumprimento de tarefas burocráticas delegadas pelas instituições, como é visto no discurso dos sujeitos A e B respectivamente:

“[...] O que me levou a ser, foi pra preencher a vaga. Tinha uma vaga lá no conselho que tinha que ser preenchida por alguém do Instituto e eu fui, não tinha conhecimento de causa e fui parar lá [...]." (SUJEITO A)

“[...] Bom, é... o que me tornou assim..., eu tenho que participar do conselho! Faz parte aqui da (instituição) grifo nosso a gente participar de todos os conselhos de direito que tem pra pessoa com deficiência. A (instituição) exige a gente seja conselheira [...]." (SUJEITO B)

\section{Trajetória ligada aos vínculos afetivos}

A segunda hipótese é a de que os atores entrevistados se envolveram na causa da pessoa com deficiência por meio de vínculos afetivos, como possuir algum familiar ou amigo com deficiência. Os relatos de alguns dos entrevistados demonstram um elo direto com pessoas com deficiência, levandoos a ocuparem espaço nos conselhos, como representantes dessas pessoas. Podem ser observados nos trechos:

"[...] já havia feito alguns trabalhos na associação de deficientes motores do estado, mas não assim de forma direta assim, indireta, mas com o tempo me afastei e percebi, por sempre estar na rua, vi muitas pessoas passando por determinadas situações e no advento de um amigo que era presidente do conselho em 2006 ter falecido e ele representava a mesma instituição que eu aqui no conselho, só que eu era atleta e precisava de uma pessoa pra poder fazer a representação no lugar do que havia falecido, na época era o presidente [...]." (SUJEITO C)

\section{Transformação de um vínculo burocrático institucional ou vínculo afetivo no engajamento político}

No relato de parte dos entrevistados, foi observado que alguns deles estão inseridos na defesa dos direitos da pessoa com deficiência por terem se identificado com a luta do seguimento, mesmo na ausência da condição de ser pessoa com deficiência. Alguns deles trouxeram, em seu discurso, que o primeiro contato com os conselhos ocorreu devido à obrigatoriedade de suas instituições de trabalho. Entretanto, a partir do momento em que tomaram conhecimento sobre esse grupo social e permitiramse um envolvimento com as lutas em defesa dos direitos existentes, transformaram uma representação burocrático-institucional em um engajamento afetivo e político com os pares em defesa dos direitos humanos.

“[...] isso é normal, gente comum como representante do governo, é então aí quando chega ofício solicitando representante da secretaria - e aí faço parte da secretaria de governo quando aí o secretário me incumbiu pra representar a secretaria nesse conselho. Daí em diante, não só nesse conselho, como outros Conselhos... Conselho da Criança e Adolescente, Conselho da Mulher, só não o da terceira idade, mas o conselho... o Conselho, que é de alimentação também fiz parte, certo?! E agora as políticas e o que mais abraçou a causa foi o Conselho da Pessoa com Deficiência [...]." (SUJEITO E)

“[...] A causa que eu acredito e também, porque eu já passei por algumas experiências. Já trabalhei com surdo, já trabalhei com autista e agora trabalho com deficiência intelectual. São 
down... síndrome de Asperger. O interesse... por que assim... eu me considero em descobrir também, não só porque abraço essa causa, porque eu desenvolvo um trabalho que é voltado para pessoas com deficiência, né?! [...]." (SUJEITO D)

Entende-se que a deficiência não é um marcador para a representatividade das pessoas com deficiência, como é visto na heterogeneidade das trajetórias dos atores. Esses diferentes caminhos podem se refletir no comprometimento desses sujeitos junto às pessoas com deficiência, porém a trajetória não é um fator de exclusão nesse engajamento. Nota-se que o fluxo percorrido pelos atores, em alguns casos, pode ser um elemento facilitador que cria subsídios para o reconhecimento enquanto sujeito político; ou pode criar um obstáculo para alavancar as discussões de temas políticos tanto nos espaços dos conselhos como nas instituições, devido ao baixo nível de reflexão e interesse de alguns representantes.

Percebe-se que as relações com o objeto em que são imersas podem ser criadas por meio da coalizão integrada para além dos marcos normativos em que sujeitos se constituem, a partir de um habitus advindos da constituição coletiva ${ }^{19}$. No caso das lutas da pessoa com deficiência, existe uma bioidentidade marcada na condição da deficiência que pode ser um facilitador para a organização política pela vivência real dos processos de exclusão; mas também existe uma necessidade latente de proposição de pautas que agreguem o grupo em torno de um movimento político independentemente das marcas no corpo ${ }^{5}$.

Um estudo sócio-histórico analisou a gênese da política de controle da aids no Brasil e recorreu à sociologia reflexiva de Bourdieu para a compreensão do espaço, agentes, trajetórias sociais, disputas e interesses. A trajetória social, no caso dessa política, surge como um importante elemento para a compreensão dos principais interesses e os acúmulos de capital científico, burocrático e político naquilo que os autores compreendem por "Espaço Aids no Brasil". A pesquisa demonstra grande heterogeneidade dos agentes, e que a participação de militantes de movimentos sociais e do movimento sanitarista tiveram grande importância na constituição do espaço Aids ${ }^{20}$.

Um estudo que analisou a formulação da política de saúde da população negra em Salvador à luz do Ciclo da Política revelou que os grupos sociais que atuaram na composição da política são muito heterogêneos; mas que, no entanto, muitos destes atores transitaram, ao longo de sua atuação, entre os espaços governamentais e não governamentais, o que reflete, inclusive, certa capacidade de mobilização e pressão política por parte das organizações da sociedade civil sobre a burocracia estatal, influenciando o trabalho dos técnicos e consultores da política, bem como as decisões dos gestores e coordenadores de programas e projetos. Assim, os atores envolvidos conseguiram dar visibilidade a problemas historicamente negligenciados e incluí-los na agenda política da saúde ${ }^{21}$.

Um estudo do tipo survey, realizado com 29 conselheiros de direitos da pessoa com deficiência e 21 especialistas em políticas públicas e gestão governamental, apontou que, para os conselheiros, a deficiência é uma questão social que deve ser compartilhada na sociedade; ao passo que, para os gestores, trata-se, sobretudo, de uma tragédia pessoal circunscrita à esfera individual e familiar. Foi considerado que a maioria dos conselheiros possuía alguma deficiência, em contrapartida aos gestores, que não possuíam. Portanto, o estudo mostra que a visão diferenciada pode se refletir de perspectivas diferentes em relação às formas de pressão sobre o Estado e à alocação dos recursos públicos?

\section{Concepção da política de saúde para a pessoa com deficiência}

Observou-se que as narrativas dos sujeitos transitaram entre dois paradigmas de relação da pessoa com deficiência com a sociedade, conceituados como Integração e Inclusão Social22.

Para alguns entrevistados, a política pública de saúde se reduz a uma visão assistencialista com auxílios individuais e pontuais. Nos relatos coletados, afirmavam que o atendimento à pessoa com deficiência deveria ser feito em centros especializados e exclusivos para a circulação dessas pessoas, equiparando ao paradigma da integração, como é visto logo a seguir. 
“[...] vamos dizer aqui é só para pessoa com deficiência, tem neurologista... tem... mas o público daqui vai ser só pessoa com deficiência, não sei se isso facilitaria [...] um centro. Pronto, pronto!! Um centro, certo, especializado [...] mas um centro especializado, entendeu?! Que ali não colocasse pessoas ditas normais... fosse só pra atender eles... que existisse um trabalho voltado mais pra isso [...]." (SUJEITO B)

"[...] a gente aqui (instituição para pessoa com deficiência) conta com o trabalho de uma médica pediatra e a gente sempre colocou isso nos relatórios, porque a gente sempre achava que isso era um "plus", esse trabalho da instituição, como a gente trabalha com criança, a gente tem um pediatra aqui, que eu acho ótimo, porque o que as mães mais reclamam é que tem dificuldade de encontrar pediatra em postos de saúde, no caso das pessoas com deficiência que tem dificuldade de marcar pra neuro ou pra psiquiatra [...] e a gente achava que isso era, sabe... o ápice da instituição [...]." (SUJEITO F)

Outro pensamento relatado por parte dos entrevistados é a concepção de direito da pessoa com deficiência. A visão de que as pessoas com deficiência são cidadãos, possuindo, assim, direitos e deveres garantidos pela legislação, apareceu nas entrevistas de conselheiros que agregam, em seus discursos, o paradigma da inclusão social, compreendendo a saúde e sua interação com outros aspectos sociais, como a educação.

“[...] É um direito, né? E tá lá na Constituição, um direito de todo o cidadão ser muito bem atendido, de que não só as pessoas com deficiência chegue... possa chegar no posto encontrar sua fralda descartável, que encontre a sua medicação, que esse médico, que é da família, esteja fazendo a visita, tendo cuidado com essas famílias, o que está acamado, a pessoa idosa que precisa do cuidado que é outro... outra referência que a gente tem que tá cuidando também, certo, existe a mobilidade reduzida que não são tratados direito [...] a gente fala muito de saúde, mas se não tiver educação não existe a saúde, né... então em primeiro lugar a educação, educação para a inclusão dessas pessoas. Traçar essa política e essa conscientização também das pessoas, inclusive as famílias [...]." (SUJEITO E)

O reconhecimento de que todos são iguais perante o Estado, porém diferentes no âmbito da diversidade humana, tão discutido no paradigma da inclusão social, é defendido por algumas falas, apontando a presença de posicionamentos com o entendimento de que a deficiência é determinada pelo contexto social23.

No Brasil, a transição de paradigmas da institucionalização, integração social até a inclusão social ainda ocorre de maneira lentificada, de modo que, nos dias atuais, o que se vê são espaços que se rotulam inclusivos, porém de forma fantasiosa, isolando sujeitos devido à falta de recursos tanto materiais quanto humanos.

\section{Necessidades de saúde}

Observou-se que os atores possuem o entendimento de que as pessoas com deficiência, assim como qualquer outro grupo social, têm necessidades de saúde, trazendo, em seus discursos, que existe uma carência de serviços especializados de saúde e suprimentos da deficiência -que envolve medicamentos, sondas, próteses e órteses - que precisa ser suprida, como é constatado nos trechos:

"[...] "por que falta fralda descartável?", "por que falta sonda dentro dos postos de saúde?", "o médico da família tá indo visitar esse deficiente que tá acamado?", "idoso também, a assistente social tá indo também?". Quer dizer, tudo isso é uma política que a gente tem que tá diariamente fiscalizando [...]." (SUJEITO E) 
“[...] no meu caso, né... a falta de atendimento especializado para o surdo, que não tem, em local nenhum a gente encontra um interprete de libras pra facilitar a comunicação entre eles e a pessoa da saúde [...]." (SUJEITO A)

Quando se fala em necessidades de saúde, os sujeitos apontam imediatamente para o que viria a ser suas demandas: as lacunas dos serviços de saúde e direito a insumos. No entanto, as necessidades de saúde ultrapassam esses limites ${ }^{3}$. No discurso dos representantes das instituições transparece um desconhecimento da amplitude do que se faz essencial às pessoas do grupo social ressaltado, se limitando às demandas exclusivas da deficiência e se igualando ao pensamento de indivíduos que acreditam que pessoas com deficiência só possuem necessidades no tocante ao corpo biológico, não acreditando numa vida plena e efetiva na sociedade.

É preciso levar em consideração a convergência do discurso dos atores em relação às dificuldades no acesso e utilização dos serviços de saúde, e a necessidade de serviços especializados em reabilitação; no entanto as exclusividades de serviços podem também ser um obstáculo para a inclusão social, sabendo-se que, por mais que existam necessidades e demandas específicas, é preciso que os movimentos sociais e atores da sociedade civil se juntem em prol de um SUS para todos.

Foi observada, também, a importância da legislação da política de saúde, porém é nítido, nos discursos, uma insatisfação na aplicabilidade e execução, especialmente pelas dificuldades de acesso.

"[...] O SUS consegue abranger, consegue atender todo o suporte. Única coisa que todo mundo questiona, e é uma verdade, é a questão financeira do SUS, mas o SUS o programa, cobertura das necessidades, cobertura dos procedimentos, o SUS dar esse suporte sim [...]." (SUJEITO G)

“[...] eu acho que na nossa lei, as políticas públicas da pessoa com deficiência, eu acho que tem tudo de bom, só falta funcionar. A gente não precisa fazer tantas coisas ainda. É só fazer que isso aconteça, verdadeiramente acontecer [...]." (SUJEITO D)

“[...] Deveria é... funcionar de forma efetiva como realmente está no papel. Se ele funcionasse da forma que ele está, dá..dá formação de lei, nós não teríamos toda essa gama de problemas que nós encontramos hoje, da questão da prioridade, da falta de medicamentos, problema de atendimento com...com...com pessoas que não querem atender da forma adequada os pacientes [...]." (SUJEITO C)

Outro ponto a ser considerado é a crítica, por parte dos entrevistados, de que as políticas da pessoa com deficiência são formuladas sem a participação daqueles que vivenciam diariamente a deficiência, como é visto abaixo:

“[...] meu olhar, as coisas, às vezes... agora assim, tem um novo olhar, diferente... as coisas deveriam ser construídas por aqueles que sentem a causa, que tem a dificuldade e não vim de alguém que nunca passou pela dificuldade da necessidade do uso de uma rampa, da necessidade de tá no posto de saúde [...]." (SUJEITO A)

Para que ocorra a efetividade da política, faz-se necessária a mobilização de várias instâncias, como de forças políticas organizadas (grupos sociais de pressão) ${ }^{17}$. Um estudo realizado no Brasil acerca do dilema da alocação de recursos públicos para a assistência à saúde das pessoas com deficiência observou que, em razão de sua vulnerabilidade, as pessoas com deficiência devem ser protegidas pelo Estado; e que, apesar da previsão de recursos já existente, a efetiva destinação destes depende de outros fatores, tais como a participação sociopolítica das pessoas com deficiência na pactuação das políticas de saúde?.

A atenção às pessoas com deficiência transcende à garantia de direitos, ela exige a dignidade e respeito humano. É notório o prejulgamento sobre a identidade da pessoa com deficiência, com a negação das necessidades sociais e de saúde dessas pessoas, que ocorre tanto pela sociedade quanto 
pelo próprio grupo social. A noção de deficiência é marcada pela insolubilidade do próprio grupo social, com marcas do individualismo de cada deficiência, o que sustenta, na maioria das vezes, o assistencialismo material e social ${ }^{23}$.

Fica, portanto, um grande desafio colocado aos movimentos sociais ligados ao campo da deficiência, o de fortalecerem seus laços de identidade e proporem temas na agenda política de saúde; bem como, o Brasil, mediante o SUS, sobretudo seu ente gestor local, construir articulações para garantir um processo de formulação e implementação de uma política pública incluindo os diversos atores sociais.

\section{Janela de Oportunidades}

A janela de oportunidades consiste em um conjunto de condições favoráveis a alterações governamentais, decisão e à entrada de novos temas na agenda ${ }^{24}$. Essas condições favoráveis são representadas pela junção de fatores como indicadores sociais e problemas concomitantes com as propostas de soluções elaboradas por especialistas e/ou funcionários públicos e o momento em que o governo vive sob a influência de pressões de grupos sociais ${ }^{24}$.

O Plano Viver sem Limite pode ser considerado uma janela de oportunidades, pois foi criado enquanto resposta às pressões sociais para a discussão de novas propostas e espaço na sociedade para as pessoas com deficiência. No entanto, é preciso compreender que as políticas, planos e programas podem sofrer refrações no âmbito local, e por isso o seu processo de formulação e implementação é inacabado, já que existem determinações locais e correlações de forças entre os distintos atores.

Os relatos coletados mostram que os entrevistados aparentemente possuem algum conhecimento sobre o Plano Viver sem Limite, porém eles não identificaram que essa oportunidade poderia ampliar a visibilidade das pessoas com deficiência, garantindo seus direitos por meio de novos projetos nas três esferas do governo. Seguem, abaixo, trechos:

“[...] Quando a gente tem alguma coisa, a gente busca se tá dentro do plano, como é que não tá. Teve algumas ações voltadas pra inscrições de cursos para a pessoa com deficiência, mas depois morreu e ficou por aí mesmo. Entra em contato com o conselho municipal ou com a menina... acho que é (Maria) grifo nosso, que é do conselho de direitos humanos, que trouxe o plano pra cá, que detalhou pra gente[...]." (SUJEITO A)

“[...] Esse ano mesmo a gente já teve fazendo visita na UBS... do atendimento até a acessibilidade, a gente tem todo esse olhar clínico, certo. E ainda tem outras pra fazer [...]." (SUJEITO E)

Coelho ${ }^{25}$ afirma que "a capacidade de um grupo social impor suas demandas nas pautas de negociação, ou seja, ter assegurado pelo Estado o enfrentamento de seus problemas por meio de políticas públicas, depende da conjuntura política e econômica. Contudo, é importante nesse processo formar sujeitos coletivos, constituindo-se autonomamente na esfera política para integrarem a base de sustentação e imporem projetos contrários ao do capital" 25 (p. 146).

\section{Conformação da Agenda Política}

Os atores ficaram divididos quanto à participação na agenda política, gerando dois grupos que compreendem de diferentes formas os espaços dos conselhos. Houve o entendimento do conselho enquanto "Espaço burocrático institucional", uma vez que alguns dos atores entrevistados contribuem com a construção da pauta das reuniões ordinárias do conselho, com demandas pontuais e, na sua maioria, com problemas institucionais. Estes atores trazem, em seus relatos, que, na maioria das vezes, não solicitam a inclusão de assuntos na pauta, deixando a livre escolha dos temas abordados para a diretoria: 
“[...] na convocação, no exercício da convocação vem dizendo as pautas que vão acontecer. Quando a gente tem alguma coisa pra levar, leva e lá na plenária a gente abre... abre o espaço e expõe a nossa necessidade [...]." (SUJEITO A)

“[...] nesse da pessoa com deficiência em particular a gente não tá nem tão ativo, porque a gente percebe que é um conselho tão compromissado com as questões que a gente meio que (risos) relaxa, sabe? [...]" (SUJEITO F)

“[...] eu levo... eu levo algumas questões aqui... da, da instituição que trabalho [...] Tem um pai aqui, que tá precisando de uma sonda. Não conseguiu. Já tem 1 ano que ele não consegue pela saúde [...]." (SUJEITO D)

Os relatos conduzem à ideia de que os representantes das pessoas com deficiência são coadjuvantes, e não os protagonistas na produção de pautas das políticas públicas da pessoa com deficiência, assumindo os conselhos como espaços burocráticos institucionais para a resolução de demandas pontuais.

Quando se trata dessa participação de representantes da pessoa com deficiência no controle social do SUS, foi constatado, nas entrevistas, que todos os atores participantes desta pesquisa afirmam a ausência dos mesmos nas reuniões dos conselhos de saúde, pois alegam não existir um convite aos conselheiros da pessoa com deficiência, não havendo, assim, a participação de nenhum representante da pessoa com deficiência nesses espaços.

“[...] Não, que a gente termina achando que esses conselhos é que vão fazer essa intermediação, sabe?! Entendeu?! Que realmente, de fato você colocando agora, ficaria mais fácil se a gente chegasse dentro do conselho da saúde e colocar essas questões, diretamente [...]." (SUJEITO F)

"[...] nós não temos nenhum contato com o Conselho de Saúde. Nem o municipal, nem estadual, nem de outra esfera. Desde que estou no conselho, que estou 8 anos, nunca veio nenhum contato do conselho de saúde, na verdade eles deveriam nos procurar pra podermos passar as orientações necessárias pra que foquem no conselho, pra poder prestar o serviço de qualidade, tanto às pessoas com deficiência, quanto a população em comum [...]" (SUJEITO C)

O primeiro passo para exercer o controle social é a plena participação nas reuniões dos diversos conselhos, pois é por meio dos movimentos sociais nesses espaços que há a construção da política de saúde ${ }^{8}$. O desconhecimento para a proposição de temas na agenda política gera um enfraquecimento da política existente ou a ser formulada, sendo assim marginalizada pelo próprio Estado.

Sabe-se que a presença da sociedade civil nos conselhos de saúde é de grande valia para a melhoria do SUS, pois são nesses espaços onde são tomadas as decisões, havendo a construção e reformulações de políticas públicas de saúde. A ausência de representantes da pessoa com deficiência em espaços com poder deliberativo deixa ainda mais à margem da agenda política do governo as problemáticas para a garantia dos direitos desse grupo social, consequentemente, gerando um maior esquecimento quanto aos direitos da pessoa com deficiência.

\section{Conclusão}

O entendimento da deficiência, por parte dos representantes da sociedade civil da pessoa com deficiência, é difuso, transitando entre os paradigmas existentes, com o destaque da integração e inclusão social. É necessário ascender o debate em relação à deficiência e construir caminhos convergentes que podem gerar um fortalecimento do grupo social, criando-se um cenário de lutas com propósitos mais coesos. 
Foi notável a carência de propostas de temas para a agenda política por grande parte dos representantes das pessoas com deficiência, havendo um distanciamento na participação da formulação e implementação da política pública de saúde. Apesar de existir um caráter fiscalizador de políticas anteriores, os representantes das pessoas com deficiência não têm visibilidade do que pode ser melhorado ou modificado. Pode-se afirmar que existe um distanciamento dos órgãos que realmente têm o poder de decisão, dificultando a articulação de ideias de atores essenciais, como a sociedade civil e os gestores representativos do Estado.

A mobilização e pressão política que parte dos movimentos sociais é de caráter decisório para a conquista dos direitos sociais, porém salienta-se a importância do engajamento entre os membros dos movimentos. Faz-se necessária maior articulação entre os próprios atores sociais, para assim defenderem as mesmas ideias do movimento social, ganhando força para superar a exclusão social existente na sociedade.

\section{Colaboradores}

Marcus Valerius da Silva Peixoto e Géssica Santana Santos participaram ativamente no planejamento da pesquisa, coleta e análise dos dados, discussão dos resultados e aprovação da versão final do trabalho. Gabriela Rodrigues Dourado Nobre, Ana Paula de Souza Novais e Paloma Martins Reis participaram ativamente da discussão dos resultados, da revisão e da aprovação da versão final do trabalho.

\section{Referências}

1. Diniz D. O que é deficiência? Coleção Primeiros Passos. São Paulo: Brasiliense; 2007. p. 324.

2. Resende APC, Vital FMDP. A Convenção sobre os Direitos das pessoas com deficiência comentada. Brasília: Secretaria Especial dos Direitos Humanos; 2008. p. 164.

3. Othero MB, Ayres JR. Necessidades de saúde da pessoa com deficiência: a perspectiva dos sujeitos por meio de histórias de vida. Interface (Botucatu). 2012; 16(40):219-33.

4. Instituto Brasileiro de Geografia e Estatística. Censo Demográfico. 2010 [citado 18 Jan 2017]. Disponível em: http://censo2010.ibge.gov.br

5. Campos MF, Souza LADP, Mendes VLF. A rede de cuidados do Sistema único de saúde à saúde das pessoas com deficiência. Interface (Botucatu). 2015; 19(52):207-10.

6. Ribeiro C, Ribeiro M, Araújo A, Mello L, Rubim L, Ferreira J. O sistema público de saúde e as ações de reabilitação no Brasil. Rev Panam Salud Publica. 2010; 28(1):43-8.

7. Bernardes LCG, Maior IMMDL, Spezia CH, Araujo TCCF. Pessoas com deficiência e políticas de saúde no Brasil: reflexões bioéticas. Cienc Saude Colet. 2009; 14(1):31-8.

8. Correia MVC. Que controle social? Os conselhos de saúde como instrumento. 2a ed. Rio de Janeiro: Fiocruz; 2003. p. 164.

9. Rolim LB, Cruz RSBLC, Sampaio KJAJ. Participação popular e o controle social como diretriz do SUS: uma revisão narrativa. Saude Debate. 2013; 37(96):139-47.

10. Chaves AC, Souza D, Fiuza P. Arquitetura da participação no Brasil: uma leitura das representações políticas em espaços participativos nacionais. Inst Pesqui Econ Apl. 2012; 1735:7-42.

11. Perfil dos Conselhos de Direito da Pessoa com Deficiência. Brasília-DF: CONADE; 2014. p. 50.

12. Inês $M$, Bravo S, Valéria $M$, Correia C. Desafios do controle social. Serv Soc Soc. 2012; 109:126-50. 
13. Gomes EGM. Conselhos gestores de políticas públicas: aspectos teóricos sobre o potencial de controle social democrático e eficiente. Cad EBAPEBR. 2015; 13(4):894-909.

14. Organzação Mundial da Saúde. Banco Mundial.Relatório mundial sobre a deficiência. São Paulo:SEDPcD; 2012. p. 334.

15. Presidência da República (BR). Decreto no 7.612, de 17 de Novembro de 2011. [Internet]. Brasília-DF: Diário da República, 1a série - no 116; 2015. p. 3901-2. Disponível em: https://dre.pt/application/file/67508032

16. Ministério da Saúde (BR). Portaria no 793, de 24 de Abril de 2012. Institui a Rede de Cuidados à Pessoa com Deficiência no âmbito do Sistema Único de Saúde. Brasília-DF; 2012.

17. Pinto I, Vieira-da-Silva LM. Ciclo de uma política pública de saúde: problematização, construção da agenda, institucionalização, formulação, implementação e avaliação. In: Paim JS, Almeida-Filho N, editores. Saúde Coletiva: teoria e prática. Rio de Janeiro: MedBook; 2014. p. 69-81.

18. Minayo MCS. O desafio do conhecimento. São Paulo: Hucitec; 2010. p. 407.

19. Pinnel P. Análise sociológica das políticas de saúde. Rio de Janeiro: Fiocruz; 2011. p. 250.

20. Barros SG, Vieira-da-Silva LM. The genesis of the AIDS policy and AIDS Space in Brazil (1981-1989). Rev Saude Publica. 2016; 50:1-13.

21. Araújo MVR, Teixeira CF. A participação dos atores na formulação da política de saúde da população negra na cidade de Salvador. Physis. 2013; 23(4):1079-99.

22. Aranha M. Paradigmas da Relação da sociedade com as pessoas com deficiência. Rev Minist Publico Trab. 2001; 21:160-73.

23. Pereira S, Lima IMSO, Pinto I. Integralidade como eixo de atenção à saúde da pessoa com deficiência. In: Pereira S, Lima IMSO, Pinto I. Política públicas e pessoa com deficiência: Dieritos humanos, familía e saúde. Salvador: Edufba; 2011. p. 93-114.

24. Pinto I. Formulação de políticas públicas: a perspectiva da teoria do ciclo da política. In: Pereira S, Lima IMSO, Pinto I. Política públicas e pessoa com deficiência: Dieritos humanos, familía e saúde. Salvador: Edufba; 2011. p. 135-53.

25. Coelho JS. Construindo a participação social no SUS: um constante repensar em busca de equidade e transformação. Saude Soc. 2012; 21 Supl 1:138-51.

Peixoto MVS, Santos GS, Nobre GRD, Novais APS, Reis PM. Análisis de la participación popular en la política de atención a la salud de la persona discapacitada en Aracaju, estado de Sergipe, Brasil. Interface (Botucatu). 2018; 22(67):1099-110.

El objetivo de este artículo es analizar el papel de la sociedad civil en la política de salud de las personas con discapacidad en el municipio de Aracaju-Estado de Sergipe. Se realizó un estudio cualitativo con entrevistas semi-estructuradas con representantes del Consejo de Defensa de los Derechos de las Personas con Discapacidad. Los datos se analizaron de acuerdo con el análisis temático de contenido. Los resultados demuestran que el entendimiento de la concepción de la discapacidad por parte de los representantes de la sociedad civil es difuso, transitando entre los paradigmas existentes. Fue notable la dificultad de los representantes en proponer temas para la agenda política en el ámbito local y participar en la formulación e implementación de la política pública de salud, creando un distanciamiento entre los órganos de control social y gestión.

Palabras clave: Formulación de políticas de salud. Control social. Políticas públicas.

Submetido em 24/04/17. Aprovado em 09/09/17. 